Proc. Indian Acad. Sci. (Chem. Sci.), Vol. 90, Number 2, April 1981, pp. 131-135.

(C) Priated in India.

\title{
2,6-Lutidine-N-oxide complexes of rare-earth bromides
}

\author{
P V SIVAPULLAIAH + and S SOUNDARARAJAN* \\ Department of Inorganic and Physical Chemistry, Indian Institute of Science, \\ Bangalore 560012 , India \\ $\dagger$ Department of Civil Engineering
}

MS received 7 October 1980

\begin{abstract}
Lutidine-N-oxide (LNO) complexes of rare-earth bromides of the composition $\mathrm{MBr}_{8}$. $(\mathrm{LNO})_{4-n} \cdot n \mathrm{H}_{2} \mathrm{O}$ where $n=1$ for $\mathrm{M}=\mathrm{La}, \mathrm{Pr}, \mathrm{Nd}, \mathrm{Sm}, \mathrm{Gd}$, Ho, $\mathrm{Er}$; and $n=0$ for $M=Y$ have been prepared and characterised by analyses, conductance and infrared data. Infrared spectra of the complexes indicate that the coordination of ligand to the metal ion takes place through the oxygen of the ligand, and the water molecule in the complexes present is coordinated to the metal. A coordination number of seven has been suggested to all the rare-earth metal ions.
\end{abstract}

Keywords. Rare-earth complexes; 2,6-lutidine-N-oxide; coordination number.

\section{Introduction}

The effect of anion on the coordination number of rare-earth metal ions is not well understood. Recently we have studied the relative effects of halide icns on the coordination chemistry of lanthanides (Koppikar et al 1978). In the dimethyl sulphoxide complexes of rare-earth halides it has been shown that rare earths attain maximum coordination number in the presence of bromide ions (Sivapullaiah and Soundararajan 1975), But in the pyridine-N-oxide complexes of rare-earth hatides the coordination number of the metal ion changes in the order $\mathrm{Cl}>\mathrm{Br}>\mathrm{I}$ which is the reverse order of ionic radii of halide ions (Sivapullaiah 1976b). However, the corresponding chloride (Vicentini and De Oliveira 1975; Sivapullaiah 1976) and iodide complexes (Ramakrishnan and Soundararajan 1977) have already been reported.

\section{Experimental}

\subsection{Materials}

Hydrated rare-earth bromides were prepared by dissolving the corresponding oxides (99.9\% pure) in aqueous solution of hydrobromic acid. After keeping the solu-

\footnotetext{
* To whom all correspondence should be made.
} 
tion overnight, the undissolved oxides were filtered off and the solution evoporated on a water-bath. The solid salts were dried in a vacuum desiccator over $\mathrm{KOH}$ pellets to remove acid vapours and subsequently dried over $\mathrm{P}_{4} \mathrm{O}_{10}$ :

Lutidine-N-oxide was obtained from Aldrich Chemical Company, USA and used as such.

The solvents uszd for the conductance measurements, methanol, DMF and acetonitrile, were purified according to standard methods.

\subsection{Preparation of the complexes}

To $0.5 \mathrm{~g}$ of the hydrated rare-earth bromide $1 \mathrm{~g}$ of the ligand was added and the mixture was stirred well. On warming on a water-bath, the salt dissolved in ligand. On further keeping the solution for about $30 \mathrm{~min}$ a crystalline product was obtained. The product was treated with acetone, filtered through a sintered crusible and washed well with acetone to remove any free ligand present. The complexes were dried over $\mathrm{P}_{4} \mathrm{O}_{10}$ in a vacuum desiccator.

\subsection{Analyses}

The metal content of the complexes was estimated by EDTA titration using xylenol orange as indicator. Bromide content was determined by Volhard's method. Lutidine-N-oxide was estimated spectrophotometrically at $253 \mathrm{~nm}$.

\subsection{Physical methods}

Molar conductances of the complexes in the methanol, DMF and acetonitrile were determined using a Siemen's conductivity bridge using an immersion cell (type LTA) previously calibrated with standard $\mathrm{KCl}$ solutions. The concentrations of the solutions used were of the order of $0.001 \mathrm{M}$. Conductance data along with analytical data are presented in table 1.

Infrared spectra of the ligand (neat) and of the complexes (in nujol mulls) were recorded on a Carl-Zeiss UR-10 infrared spectrophotometer. Important absorption bands and their assignments are given in table 2.

\section{Results and discussion}

The analytical data (table 1) show that the complexes have the general formula $\mathrm{MBr}_{3} \cdot(\mathrm{LNO})_{4-n} . \cdot n \mathrm{H}_{2} \mathrm{O}$ where $n=1$ for $\mathrm{M}=\mathrm{La}, \mathrm{Pr}, \mathrm{Nd}, \mathrm{Sm}, \mathrm{Gd}, \mathrm{Tb}, \mathrm{Ho}$, Er; and $n=0$ for $\mathrm{M}=\mathrm{Y}$. The composition of the complexes indicates that the presence of methyl groups at both 2 and 6 position introduces considerable steric hindrance and brings down the number of ligand molecules attached to the metal from eight in the pyridine-N-oxide complexes (Sivapullaiah 1976) to three or four in the present complexes. The number of ligand molecules coordinated to metal in the 2-picoline- $\mathrm{N}$-oxide complexes (where only one methyl group is attached to pyridine-N-oxide) of rare-earth bromides is five (Sivapullaiah and Soundararajan 1976).

The complexes behave as $1: 2$ electrolytes in the dimethyl formamide and methanol and as non-electrolytes in acetonitrile (Geary 1971). This suggests 


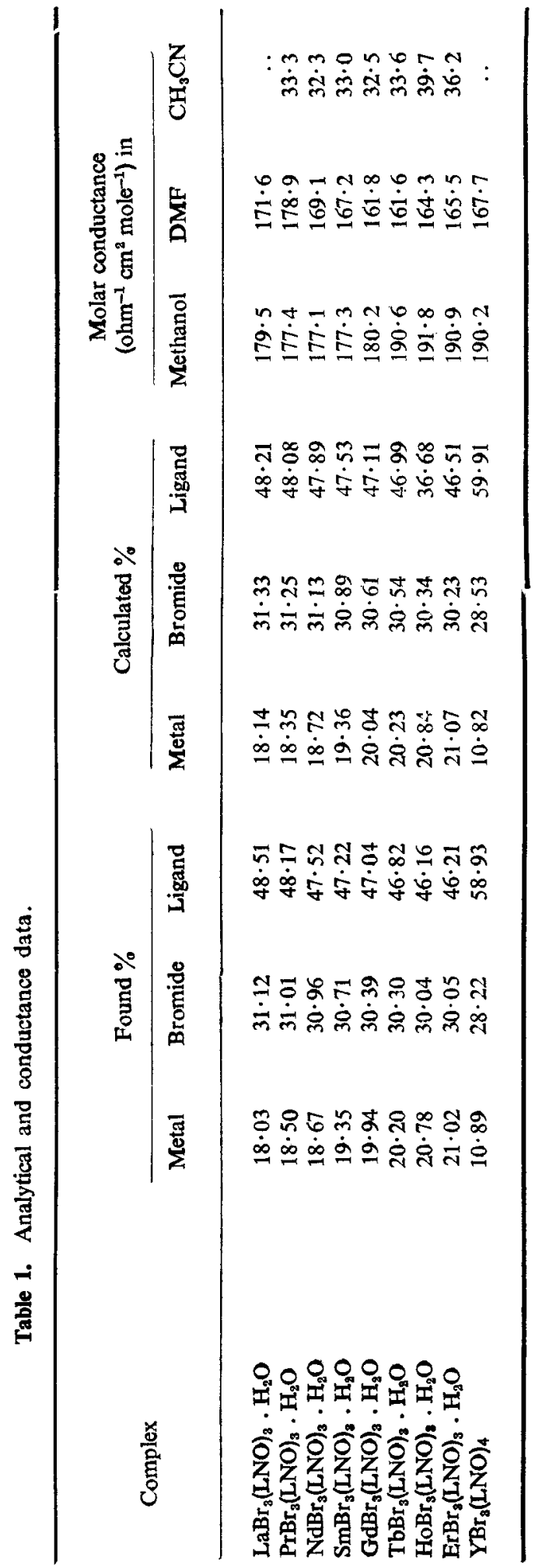


Table 2. Some important IR bands of the complexes $\left(\mathrm{cm}^{-1}\right)$

\begin{tabular}{ccl}
\hline LNO & $\mathrm{LaBr}_{3}(\mathrm{LNO})_{3}, \mathrm{H}_{2} \mathrm{O}$ & \multicolumn{1}{c}{ Assignment } \\
\hline $1504 \mathrm{~s}$ & $1502 \mathrm{~s}$ & Ring deformation \\
$1464 \mathrm{~s}$ & $1466 \mathrm{~s}$ & Ring deformation \\
$1258 \mathrm{vs}$ & $1230 \mathrm{vs}$ & $\mathrm{N}-\mathrm{O}$ stretching \\
$1164 \mathrm{w}$ & $1169 \mathrm{w}$ & $\mathrm{CH}$ in plane deformation \\
$1106 \mathrm{~m}$ & $1109 \mathrm{~m}$ & \\
$1040 \mathrm{~m}$ & 1038 & $\mathrm{Ring}$ breathing \\
$846 \mathrm{~s}$ & $846 \mathrm{~s}$ & $\mathrm{~N}-\mathrm{O}$ bending \\
$780 \mathrm{~s}$ & $785 \mathrm{~s}, \mathrm{~d}$ & $\mathrm{CH}$ out of plane vibration \\
& & \\
\hline
\end{tabular}

'Neat' spectrum LNO and spectra of its complex as $\mathrm{KBr}$ pellets are reported.

Abbreviations : vs = very strong; $\mathrm{s}=$ strong; $\mathrm{m}=$ medium; $\mathrm{w}=$ weak; $\mathrm{d}=$ doublet.

that while all the bromide ions are coordinated to the metal ion two of the bromide ions are bound differently from the third ion.

The $\mathrm{N}-\mathrm{O}$ stretching vibration of the ligand occurring at $1258 \mathrm{~cm}^{-1}$ shifts to lower frequencies indicating that the complexation of the ligand is through the oxygen of the $\mathrm{N}-\mathrm{O}$ group. The band due to $\mathrm{N}-\mathrm{O}$ bending vibration occurring at $846 \mathrm{~cm}^{-1}$ in the ligand does not undergo any shift upon complexation. The bands in the region $3220-3350 \mathrm{~cm}^{-1}$ and the band at $1640 \mathrm{~cm}^{-1}$ appearing in the complexes where water is prosent can be assigned to $\mathrm{OH}$ stretching frequencies and $\mathrm{HOH}$ bending vibration of water respectively. The occurrence of stretching frequenzies at relatively lower frequencies and the bending frequency at a slightly higher frequency coupled with the appearance of a new band at about $640 \mathrm{~cm}^{-1}$, assignable to the rocking mode of coordinated water, leads to the conclusion that the water present in the complexes is coordinated to the metal (Sartori et al 1958).

A coordination number of seven (three ligand molecules, three bromide ions and one water molecule in the complexes of $\mathrm{La}, \mathrm{Pr}, \mathrm{Nd}, \mathrm{Sm}, \mathrm{Gd}, \mathrm{Tb}, \mathrm{Ho}, \mathrm{Er}$; and four ligand molecules and three bromides ions in the yttrium complex) has been suggested to all rare-earth ions. Coordination number of lanthanides in the corresponding chlorides is not reasonably established. However, a coordination number of five has been indicated in these complexes.

In the corresponding iodide complexes dimeric structures involving bridging amine oxide groups have been assigned with coordination number of metal ion being either six or seven. Thus in the lutidine- $\mathrm{N}$-oxide complexes of rare-earth halides the coordination number is only marginally higher in the bromide complexes.

\section{Acknowledgement}

One of the authors (PVS) thanks the authorities of the Indian Institute of Science for financial assistance. 


\section{References}

Geary W J 1971 Chem. Rev. 781

Koppikar D K, Sivapullaiah P V, Ramakrishnan L and Soundararajan S 1978 Struct. Bonding 34135

Ramakrishnan L and Soundararajan S 1977 Monatsh. Chem. 108225

Sartori G, Furlani C and Damiani A 1958 J. Inorg. Nucl. Chem. 8119

Sivapullaiah P V 1976 Ph.D. Thesis, Studies in rare-earth chemistry, Indian Institute of Science, Bangalore

Sivapullaiah P V and Soundararajan S 1975 Curr. Sci. 44374

Sivapullaiah P V and Soundararajan S 1976 J. Inorg. Nucl. Chem. 381402

Vicentini $G$ and De Oliveira W 1975 J. Inorg. Nucl. Chem. 372018 